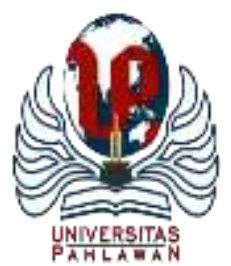

\title{
JURNALBASICEDU
}

Volume 5 Nomor 6 Tahun 2021 Halaman 5234 - 5240

Research \&Learningin Elementary Education

https://jbasic.org/index.php/basicedu

\section{Penanaman Karakter Smart Young And Good Citizen untuk Anak Usia Sekolah Dasar}

\author{
Dinie Anggraeni Dewi ${ }^{1 凶}$, Solihin Ichas Hamid ${ }^{2}$, Jenisa Tasya Kamila ${ }^{3}$, Salsa Berliana Putri ${ }^{4}$, Vesha \\ Nuriefer Haliza ${ }^{5}$ \\ Universitas Pendidikan Indonesia, Indonesia ${ }^{1,2,3,4,5}$ \\ E-mail: dinieanggraenidewi@upi.edu ${ }^{1}$; solihinichas@ @upi.edu $^{2}$, jenisatasya@ upi.edu ${ }^{3}$; $\underline{\text { alsaberliana @ upi.edu }}^{4}$, \\ veshanh@upi.edu ${ }^{5}$
}

\begin{abstract}
Abstrak
Generasi bangsa yang cerdas dan memiliki akhlak baik serta berkepribadian Indonesia dapat diwujudkan melalui pendidikan karakter. Suatu bangsa agar mempunyai karakter, pembalajaran PKn sangat dibutuhkan khususnya anak usia dasar untuk menumbuhkan sikap warga negara yang diharapkan bangsa dan bertujuan untuk membentuk karakter siswa untuk bersikap, bertindak, berfikir, berinteraksi, dan berkembang, berpartisipasi aktif, serta mempunyai tanggung jawab diri dan lingkungannya, masyarakat, juga dalam berbangsa dan bernegara. Penelitian berjudul "Penanaman Karakter Smart Young And Good Citizen Untuk Anak Usia Sekolah Dasar"dengan tujuan untuk menanamkan karakter sebagai warga negara yang baik. Dalam pembelajaran PKn, terdapat suatu target utama yakni sebagai bekal pengetahuan, membina sikap dan perilaku, serta latihan keterampilan menjadi warga negara yang demokratis, taat asas, dan taat hukum dalam kehidupan lingkungan masyarakat. Warga negara muda merupakan calon pemimpin masa depan, maka dari itu penanaman karakter perlu dibekali sejak dini hal ini sangat penting dan menjadi suatu kewajiban untuk terus menerus dilakukan oleh keseluruhan warga negara untuk harapan dan masa depan bangsa Indonesia. Warga negara yang mempunyai keterampilan dan sikap akan menjadikan dirinya sebagai warga negara yang berkomitmen. Maka dari itu,pentingnya pembelajaran PKn untuk membangun genarasi muda smart and goodcitizen. Penelitian ini akan dilakukan dengan metode studi literatur yang mana penelitian artikel ini berbasis pada jurnal, buku, dan lain lain.
\end{abstract}

Kata Kunci: Karakrter. Anak Usia Sekolah Dasar, Warga Negara Muda Cerdan dan Baik

\begin{abstract}
The generation of a nation that is intelligent and has good morals and Indonesian personality can be realized through character education. In order for a nation to have character, Civics learning is needed, especially for elementary age children to foster the attitude of citizens expected by the nation and aims to shape the character of students to behave, act, think, interact, and develop, participate actively, and have responsibility for themselves and their environment. , society, as well as in the nation and state. The research entitled "Creating Smart Young And Good Citizen Characters for Elementary School Age Children" with the aim of instilling character as a good citizen. In Civics learning, there is a main target, namely as a provision of knowledge, fostering attitudes and behavior, as well as training skills to become a democratic, principle-abiding, and law-abiding citizen in the life of the community. Young citizens are candidates for future leaders, therefore character building needs to be equipped from an early age. This is very important and becomes an obligation to be continuously carried out by all citizens for the hope and future of the Indonesian nation. Citizens who have the skills and attitudes will make themselves as committed citizens. Therefore, the importance of Civics learning is to build the young generation of smart and good citizens. This research will be conducted using a literature study method where the research of this article is based on journals, books, and others.
\end{abstract}

Keywords: Character, Elementary AgeChildren, Smart and GoodYoungCitizen

Copyright (c) 2021 Dinie Anggraeni Dewi, Solihin Ichas Hamid, Jenisa Tasya Kamila, Salsa Berliana Putri, Vesha Nuriefer Haliza

$\triangle$ Corresponding author :

Email : dinieanggraenidewi@upi.edu

DOI : https://doi.org/10.31004/basicedu.v5i6.1614

ISSN 2580-3735 (Media Cetak)

ISSN 2580-1147 (Media Online) 
5235 Penanaman Karakter Smart Young And Good Citizen untuk Anak Usia Sekolah Dasar - Dinie Anggraeni Dewi, Solihin Ichas Hamid, Jenisa Tasya Kamila, Salsa Berliana Putri, Vesha Nuriefer Haliza

DOI: https://doi.org/10.31004/basicedu.v5i6.1614

\section{PENDAHULUAN}

Setiap bangsa memiliki karakter yang dapat dibedakan bangsa satu dengan bangsa lainnya. Pendidikan karakter inilah yang menjadi suatu hal yang harus dilakukan karena semua pendidik atau guru mempunyai kesamaan tujuan untuk membentuk karakter suatu bangsa. Pendidikan karakter ini tidak secara serta merta menjadi tanggung jawab pendidikan moral dan pendidikan Pancasila (Santika et al., 2019). Dengan demikian, karakter siswa di masa mendatang menjadi suatu kepentingan dalam pengembangan konsep pendidikan kewarganegaraan yang termasuk di dalam suatu proses pendidikan sekolah dasar. Pembentukan karakter adalah segala sesuatu yang dilakukan guru untuk mempengaruhi karakter siswa. Guru membantu meningkatkan karakter siswa, guru membantu meningkatkan karakter siswa dengan memberikan contoh, cara berbicara, atau materi yang baik (Ma'mur, 2016). Mata pelajaran Pendidikan Kewarganegaraan (PKn) menjadi suatu mata pelajaran yang di dalamnya mengandung ajaran-ajaran nilai moral yang mempunyai peran serta dalam membentuk karakter siswa yang diharapkan dapat menjadi warga negara aktif, baik, dan cerdas (smart young and good citizen). Pendidikan Kewarganegaraan mempunyai tujuan dalam pengembangan pendidikan demokrasi secara sosiopedagogis dan sosio andragogis yang dapat membentuk warga negara yang cerdas (Winataputra, 2016).

Kajian ini merupakan kajian dalam rangka pengenalan Pendidikan Kewarganegaraan di sekolah dasar dengan membahas kewarganegaraan yang smart young and good citizen. Pendidikan kewarganegaraan sebagai pendidikan nilai, artinya pendidikan kewarganegaraan termasuk pendidikan dalam nilai atau moral. Salah satu dari tujuan pendidikan kewarganegaraan adalah warga negara memahami nilai-nilai hukum dan mampu berperilaku sesuai dengan nilai hukum yang sama muncul dari hati nurani masyarakat, sehingga nilai hukum itu sendiri adalah nilai moral, menurut ketentuan hukum yang baik bila sesuai dengan nilai hukum yang dianggap baik oleh masyarakat, yang dinilai atas dasar moral (Suradi, 2019). Sedangkan menurut (Samsuri, 2011) Pendidikan Kewarganegaraan diartikan sebagai pembelajaran untuk mempersiapkan generasi muda menjadi warga negara yang memiliki pengetahuan, keterampilan, dan nilai-nilai yang diperlukan untuk berinteraksi dalam masyarakat yang baik. Mata pelajaran ini mempunyai tujuan utamanya dalam memberikan esensi demokrasi dalam mencapai kompetensi aspek-aspek kewarganegaraan. Oleh karena itu, penguatan penanaman karakter yang baik bagi siswa sekolah dasar ini tidak serta merta mudah, namun harus konsisten dan juga berkomitmen secara kesinambungan. Sekolah dasar sebagai pendidikan jenjang pertama berfungsi sebagai pondasi bagi peserta didik untuk mempunyai daya saing dan kepribadian bangsa. Kewarganegaraan yang smart, young, and good citizen ini menuju pada konsep karakter bangsa yang baik, terdiri dari beberapa aspek yang saling berkaitan.

Peran mata pelajaran Pendidikan Kewarganegaraan sudah menjadi konsep yang integratif yang berpusat pada peserta didik. Pendidikan karakter ini jika diterapkan di sekolah dasar dapat menjadi suatu keberlangsungan pendidikan ke tahap-tahap selanjutnya. Peran dalam membentuk generasi yang utuh dan mempunyai kecerdasan yang luas, sikap yang baik, ketrampilan dalam kehidupan masyaraakat merupakan peran adanya pendidikan. Maka dari itu dalam suatu proses pembelajaran, peran guru wajib dan harus mampu sebagai fasilitator yang mampu mengidentifikasi segala kelebihan dan kekurangan bentuk pembelajaran yang nantinya akan diterapkan kepada siswa, sehingga harus benar-benar memberikan suatu pembelajaran yang efektif (Sardiman, 2020).

Pendidikan Kewarganegaraan ini diharapkan dapat memberi pendidikan karakter bangsa kepada generasi milenial yang dapat menjaga persatuan bangsa. Kualitas pendidikan yang semakin menurun menjadi tuntutan bagi pendidikan kewarganegraan guna membentuk warga negara yang "Smart, young, and good citizen". Hal ini tak lain disebabkan oleh warga negara yang semakin hidup dengan terpengaruh bangsa lain 
5236 Penanaman Karakter Smart Young And Good Citizen untuk Anak Usia Sekolah Dasar - Dinie Anggraeni Dewi, Solihin Ichas Hamid, Jenisa Tasya Kamila, Salsa Berliana Putri, Vesha Nuriefer Haliza

DOI: https://doi.org/10.31004/basicedu.v5i6.1614

dalam pergaulan internasional. Walaupun memang di dunia ini ada beberapa bangsa di belahan dunia yang berbeda-beda.

\section{METODE PENELITIAN}

Kajian ini menggunakan metode penelitiannya yaitu studi literatur (penelitian terhadap buku, jurnal, karya tulis dll). Karena jenis metode penelitian ini bermanfaat untuk mencari informasi berdasarkan referensi teori dari informan tertentu yang relevan dengan kasus dan permasalahan yang ditemukan. Tolak ukur yang dijadikan dalam penetapan literatur ini adalah menggunakan salah satu jurnal dengan akreditasi google schoolar yang dipublikasikan pada tahun 2019. Penelitian studi literatur ini dianggap pula sebagai metode pengumpulan data bersifat kualitatif. Yakni, penelitian dengan observasi wawancara maupun kajian dokumen yang mempunyai tujuan untuk mencari, menggali, dan mengungkap data, fakta, serta makna yang ada di latar penelitian. Tahapan penelitian ini yang pertama dengan mengumpulkan jurnal - jurnal yang relevan dengan judul kemudian membaca jurnal tersebut dan mengutip kalimat kalimat yang berkaitan dengan judul.

\section{HASIL DAN PEMBAHASAN}

Pada dasarnya, guru sebagai pendidik dalam mengajarkan pendidikan karakter mempunyai tujuan dalam membentuk karakter bangsa. Poin inilah yang sesuai dengan tujuan pendidikan nasional, yakni pengembangan potensi siswa untuk memiliki akhlak mulia dan cerdas. Pendidikan ini mempunyai harapam akan dapat menciptakan generasi bangsa yang smeakin tumbuh berkembang menjadi karakter yang mempunyai nilai-nilai luhur, agama, dan bangsa. Watak seseorang disebut karakter, atau akhlak yang didapat dari interkoneksi dengan sekelilingnya. Karakter disebut baik jika karakter tersebut didasarkan atas nilai moral dan etika yang disetujui dan berlaku di lingkungan masyarakat. Wibowo(2012)"Mengungapkan bahwa cara berpikir dan bertingkah laku khas tiap individu untuk dapat bekerja sama dan hidup di dalam lingkup keluarga, lingkup masyarakat, bangsa serta negara merupakan suatu penjelasan dari karakter. Seseorang yang mempunyai karakter baik yakni mereka yang dapat membuat suatu keputusan serta dapat bertanggung jawab dalam setiap keputusan yang dibuat.

Pendidik harus sadar akan pentingnya pembentukan karakter sebagai wadah pembentukan perilaku, pengembangan nilai-nilai pribadi dengan caranya adalah menjadi panutan bagi peserta didik, dan mampu membantu melahirkan kondisi lingkungan yang kondusif bagi proses pertumbuhan secara nyaman dan aman, untuk melihat keseluruhan suasana pengembangan diri pribadi dari sudut pandang teknis. Secara intelektual, psikologis, moral, sosial,estetika dan agama.

Terdapat tiga fungsi utama dalam pendidikan karakter, yang pertama adalah fungsi pembentukan dan pengembangan potsnsi siswa. Pembentukan dan pengembangan ini tidak lain dikarenakan oleh pendidikan karakter yang dapat membentuk potensi para siswa agar perilaku, pikiran, dan hatinya sesuai dengan falsafah Pancasila. Fungsi kedua adalah perbaikan dan penguatan, hal ini dimaksukan bahwa pendidikan karakter mempunyai fungsi dalam memperbaiki dan menguatkan peran keluarga, masyarakat, pemerintah, dan satuan pendidikan untuk dapat memberi partisipasi dalam mengembangkan potensi warga negara menuju bangsa mandiri, maju, serta sejahtera. Fungsi ketiga adalah penyaring, hal ini dimaksukan pendidikan karakter memisahkan budaya bangsa dan menyaring budaya bangsa lain yang bertentangan dengan karakter dan nilai budaya bangsa (Zubaedi, 2011). Maka dari itu karakter bangsa perlu dibentuk dengan melibatkan sinergi antar tiga komponen pendidikan yakni pendidikan non formal, informal, maupun formal.

Pendidikan karakter tersebut sudah harus ditanamkan pada anak usia sekolah dasar, adalah mereka yang usianya mulai dari 6- 12 tahun dan sering dijuluki periode intelektual. Intelektual menurut ahli psikologi 
5237 Penanaman Karakter Smart Young And Good Citizen untuk Anak Usia Sekolah Dasar - Dinie Anggraeni Dewi, Solihin Ichas Hamid, Jenisa Tasya Kamila, Salsa Berliana Putri, Vesha Nuriefer Haliza

DOI: https://doi.org/10.31004/basicedu.v5i6.1614

bernama Jean Piaget adalah hasil dari adanya interaksi atau faktor sejak lahir dan lingkungan sekitar. Periode ini juga sering disebut periode keserasian sekolah. Pada anak usia sekolah dasar, pengetahuan dan keterampilan yang merekamiliki akan bertambah dengan pesat seiring dengan bertambahnya usia. Adapun minat anak pada usia ini lebih cenderung kepada sesuatu yang memiliki sifat dinamis bergerak.

Ketika anak berusia 6-7 tahun, mereka akan dianggap sudah waktunya untuk mulai masuk jenjang pendidikan sekolah dasar. Dalam periode anak sekolah dasar ini terdiri dari kelas rendah yaitukelas 1-3 dan kelas tinggi 4-6. Karakteristik antara anak SD kelas rendah dan anak SD Kelas tinggi pun berbeda. Umumnya, untuk anak SD kelas rendah memiliki karakteristik sebagai berikut:

1. Adanya hubungan dengan tingkat korelasi tinggi dan juga positif diantara keadaaan kesahatan jasmani dan perkembangan prestasi di sekolah.

2. Cenderung untuk memuji diri sendiri

3. Patuh pada aturan-aturan permainan yang ada di dunianya.

Sedangkan karakteristik anak SD kelast inggi diantaranya yaitu:

1. Memiliki minat terhadap praktis kehidupan sehari-hari yangbersifat konkret.

2. Rasa keingintahuan tentang sesuatu dan mempelajarinya sangat tinggi.

3. Ketika anak berumur 11 tahun, mereka membutuhkan seorang guru dan atau orang dewasa untuk membantu mereka dalam mengerjakan tugas-tugas.

4. Ketika umur mereka sudah melewati 11 tahun atau sekitar 12 tahun tumbuh minat terhadap suatu hal khusus atau mata pelajaran khusus yang akan mereka kembangkan menjadi bakat dimasa depan.

Sebagai seorang guru maupun calon guru harus bisa memahami terlabih dahulu bagaimana karakteristik dan perkembangan anak di usia sekolah dasar. Hal ini dimaksudkan agar seorang guru maupun calon guru dapat memilih metode pengajaran yang tepat kepada peserta didik.

Selain mempelajari dan memahami karakteristik anak usia sekolah dasar, seorang guru maupun calon guru juga harus memahami setidaknya beberapa tahap perkembangan emosional, kognitif, bahasa, dan moral.

Sekarang jaman sudah masuk diera revolusi industri 4.0 yang tentunya banyak tantangan seriing dengan perkembangan teknologi digital, sehingga perlu untuk menanamkan serta menguatkan karakter bangsa. Berkembangnya nilai-nilai individualistis, hedonism, materiaslistis menjadi beberapa contoh dampak buruk dari adanya revolusi industri 4.0 tersebut. Jika hal ini tidak ditangani secepatnya, maka dikhawatirkan akan memberi dampak buruk akan keberlangsungan hidup bangsa yang tidak menggambarkan nilai kepribadian bangsa. Mendesaknya jaman di era revolusi industri 4.0 penanaman karakter wajib dibekali sejak dini, karena sebagai warga negara muda merupakan calon pemimpin bangsa.

Generasi muda dijadikan sebagai andalan pembangunan berkelanjutan Indonesia masa depan (Budimansyah, 2010). Akan tetapi wawasan tentang "smart young and good citizen" dalam kalngan generasi milenial ternyata masih banyak yang belum memahami. "Smart young and good citizen" jika diartikan secara singkat yakni warga negara yang cerdas dan baik. Smart young and good citizen adalah harapan hasil akhir jika tiga komponen utama dalam pendidikan kewarganegaraan dapat dilaksanakan dengan baik. Tiga komponen tersebut yaitu pengetahuan kewarganegaraan (civic knowledge), keterampilan kewarganegaraan (civic skills), dan sikap kewarganegaraan (civic dispositions) (Arliman, 2020).

Masih banyak dijumpai generasi sekarang yang masih minim tentang pengetahuan smart young and good citizen walaupun mereka sudah mendapat pendidikan kewarganegaraan yang diajarkan di sekolah. Akan tetapi banyak juga kalangan generasi sekarang yang sudah memahami wawasan tentang smart young and good citizen. Mereka sebagai generasi muda yang masih belum memahami akan pengetahuan tersebut dapat dikatakan bahwa mereka belum meimplementasikan dengan benar nilai-nilai pendidikan kewarganegaraan dan mereka merasa belum sepenuhnya menjadi warga negara (citizen) baik. 
5238 Penanaman Karakter Smart Young And Good Citizen untuk Anak Usia Sekolah Dasar - Dinie Anggraeni Dewi, Solihin Ichas Hamid, Jenisa Tasya Kamila, Salsa Berliana Putri, Vesha Nuriefer Haliza

DOI: https://doi.org/10.31004/basicedu.v5i6.1614

Permasalahan ini harus segera diselesaikan mengingat hal ini berkaitan dengan hidup bangsa Indonesia. Jika masih ditemukan munculnya kesadaran dalam diri mereka bahwa belum dapat menjadi warga negara baik secara utuh, maka diharapkan akan sangat mudah bagi generasi muda tersebut dalam meningkatkan kesadarannya guna menjadi warga negara yang "smart young and good citizen". Saat ini pada genari muda memenuhi kebutuhannya dalam memperoleh informasi dan interaksi berjalan sesuai dengan kecanggihan teknologi. Contohnya ditandai dengan adanya itentsitas tinggi dari penggunaan internet. Terdapatnya bantuan konektivitas internet memudahkan para generasi muda dalam mencari dan mengatahui pengetahuan mengenai smart young and good citizen berkaitan dengan pendidikan kewarganegaraan. Selain itu, berfungsinya internet dapat membantu generasi muda dalam meningkatkan kesadaran mereka agar menjadi warga negara yang "smart young and good citizen". Informasi-informasi tersebut dapat didapatkan melalui akses sosial media.

Generasi sekarang atau sering dikenal generasi milenial seharusnya sudah tahu dan menjadi warga negara yang "smart young and good citizen" untuk kepentingan mencapai keberlangsungan bangsa yang maju. Era disrupsi sekarang ini harus menjadi era yang terdiri atas banyaknya warga negara yang berkarakter, kreatif, inovasi, pintar, serta produktif dalam rangka pengembangan bangsa Indonesia. Generasi sekarang di era 4.0 ini wajib juga mempunyai pemikiran yang dipenuhi dengan pengetahuaan kewarganegaraan agar nantinya di masa mendatang mereka dapat menjadi penerus pemimpin yang tahu betul mengenai warga dan bangsanya, juga dapat menjadi warga negara yang mengerti hak dan kewajibannya. Sehingga, generasi muda sekarang diharuskan untuk menambah wawasan mengenai smart young and good citizen.

Menurut Budimansyah (2010) menyatakan bahwa perilaku yang cerdas dan baik merupakan bagian dari karakter manusia. Karakter yang baik tersebut terdiri atas perilaku yang baik, pengetahuan yang baik dan melakukan sesuatu yang baik. Karakter "baik" dalam pandangan masyarakat Indonesia adalah mereka yang memiliki sifat-sifat kebajikan seperti jujur, mandiri, demokratis, peduli, kreatif, toleransi, dll. Sedangkan karakter yang cerdas menurut Priyanto (budimansyah,2010) mendefinisikannya sebagai keahlian dalam manipulasi beberapa unsur yang dipersiapkan dalam menghadapi kesuksesan dan mencapaitujuan.

Adapun pengertian lain dari cerdas adalah kaitan erat antara kemampuan kognitif yang dimiliki oleh seseorang. Taraf kecerdasan tergambarkan dari perilaku yang objektif, aktif, aspiratif, kreatif, inovatif, analitis, dinamis, serta antisipatif (Winarno, 2012).

Penanaman karakter smart young and good citizen ini bukan semata-mata hanya memberikan teori pengertian, tetapi harus dilakukan implementasi secara langsung kepada pesertadidik dan generasi muda. Implementasi dapat dikatakan sebagai suatu proses dalam pelaksanaan ide, pelaksanaan aktivitas dengan harapan dapat menyesuaikan tercapainya tujuan. Adapun strategi implementasi pendidikan karakter melalui smart young and good citizen adalah membuat pendidikan karakter yang dapat mengatasi permasalahanpermasalahan yang muncul karena adanya era disrupsi. Pendidikan ini nantinya akan membentuk karakter siswa "smart and good citizen" khususnya yang berada di sekolah dasar berdasarkan nilai kebangsaan Indonesia yakni pancasila dan UUD tahun 1945.

Pengimplementasian karakter siswa sekolah dasar dapat berkembang dengan baik jika diiringi dengan konsep smartand good citizen yang mendukung. Berdasarkan hasil penelitian yang dilakukan, berpendapat bahwa konsep smart young and good citizen berarti kemampuan aktif dalam menalurkan ide kreatif serta inovatif guna mencerdaskan, memajukan, dan mengembangkan bangsa Indonesia. Konsep smart young and good citizen berisi tuntutan untuk dapat menyeleksi berbagai informasi dan budaya yang datang dari luar. Sebagai contoh, dalam menerima informasi dari luar diharuskan selektif agar dapat menjaga keutuhan dan jati diri bangsa sehingga tidak mudah untuk terpecah belah.

Tujuan pendidikan karakter adalah menghidupkan kembali karakter peserta didik yang disesuaikan atas nilai pancasila, yakni diantaranya nilai keimanan, ketaqwaan, kejujuran, kepeduliaan, persatuan, sampai pada etika dan sopan santun. Pendidikan kewarganegaraan merupakan salah satu dari beberapa sarana dalam 
5239 Penanaman Karakter Smart Young And Good Citizen untuk Anak Usia Sekolah Dasar - Dinie Anggraeni Dewi, Solihin Ichas Hamid, Jenisa Tasya Kamila, Salsa Berliana Putri, Vesha Nuriefer Haliza

DOI: https://doi.org/10.31004/basicedu.v5i6.1614

rangka implementasi nilai pendidikan karakter pada siswa terutama di jenjang sekolah dasar. Hal ini dikarenakan pada dasarnya pendidikan kewarganegaraan mempunyai tujuan untuk menumbuhkan siswa sebagai warga negara berkarakter dan demokratis sesuai nilai Pancasila. Oleh karenanya, implementasi pendidikan karakter di sekolah dasar sangat tepat guna membentuk generasi muda yang mempunyai akhlak.

Sebagai contoh, Kota Bandung yang banyak dijumpai generasi muda yang paham mengenai konsep smart young and good citizen. Hal ini ditunjukan dengan adanya implementasi tindakan smart and good di lingkungannya dan di media sosial. Pemahaman generasi muda mengenai nilai pendidikan kewarganegaraan dibuktikan dari penerapan nilai itu di kehidupannya sehari-hari. Pengaruh pendidikan kewarganegaraan sangat besar dalam membentuk warga negara yang "smart young and good citizen".

Para peserta didik di sekolah dasar harus menjadi "smart and good citizen" untuk mencapai keberlangsungan dan kemajuan bangsa Indonesia. Pada intinya, peserta didik yang tidak memahami kewajibannya sebagai warga negara yang baik merupakan mereka yang tidak paham betul akan nilai-nilai yang tersirat dalam Pancasila. Merekalah yang tidak mengimplementasikan apa yang telah diajarkan dalam pendidikan kewarganegaraan.

Pemuda-pemudi di Kota Bandung yang telah mengaplikasikan pendidikan karakter dan kewarganegraan dapat dipahami bahwa mereka sudah menjadi "smart and good citizen".Terlebih di era disrupsi sekarang ini, untuk mengimplementasikan pendidikan kewarganegaraan dapat dilakukan melalui media sosial untuk mempermudah dalam interaksi ke bangsa lain dan memberi kebebasan berpendapat dan berekspresi.

Sekarang ini, banyak generasi muda yang mampu menyampaikan pendapatnya, berdiskusi untuk mencari solusi berkaitan dengan isu kewarganegaraan. Contoh inilah yang menjadi bukti bahwa generasi sekarang perlahan telah menjadi warga negara yang "smart young and good citizen". Tidak hanya itu, sikap toleransi yang tercermin juga menunjukan bahwa mereka telah mengetahui suku, ras, budaya, agama diantara golongan lain dan menjadikan perbedaan tersebut menjadi berharga.

\section{KESIMPULAN}

Pembentukan karakter bertujuan untuk mengembakan potensi siswa untuk memiliki kecerdasan, kepribadian, dan ahlak mulia. Pembentukan karakter perlu ditanami dari sejak dini, karena ini merupakan hal yang wajib dimiliki oleh warga negara muda. Sebagai pendidik wajib menanamkan dan membentuk karakter kepada siswa agar dapat melahirkan genarasi bangsa yang tumbuh dan berkembang. Para genarasi muda harus menjadi smart and good citizen, karena genarasi mudayang akan membangun dan bisa memperbaiki bangsa agar menjadi semakin lebih baik. Saat ini para peserta didik telah mampu mengaplikasikan dengan baik penanaman karakter smart and goodcitizen di lingkungannya ataupun di dunia maya dengan pendidikan kewarganegaraan dan telah memahami apa saja nilai- nilai tersirat yang ada di pendidikan kewarganegaraan, dengan mempraktekan nilai-nilai tersebut dalam kehidupannya sebagai smart and good citizen. Pengaruh pendidikan kewarganegaraan cukup besar dalam membentuk warga negara yang smart and good, jika para peserta didik mempelajarinya dengan sungguh-sungguh maka mudah bagi mereka untuk menjadi smart young and good citizen.

\section{DAFTAR PUSTAKA}

Amanullah, M. A., Nunuk, S., \& Tri, A. D. (2019). Pendidikan Kewarganegaraan (Citizenship) Sebagai Sarana Mewujudkan Warga Negara Yang Beradab (Good Citizenship). Seminar Nasional Pendidikan Pengembangan Kualitas, 66-72. 
5240 Penanaman Karakter Smart Young And Good Citizen untuk Anak Usia Sekolah Dasar - Dinie Anggraeni Dewi, Solihin Ichas Hamid, Jenisa Tasya Kamila, Salsa Berliana Putri, Vesha Nuriefer Haliza

DOI: https://doi.org/10.31004/basicedu.v5i6.1614

Haliza, V. N., \& Dewi, D. A. (2021). Pendidikan Kewarganegaraan Dalam Menjawab Tantangan Masa Depan Bangsa Ditengah Arus Globalisasi. Jurnal Pendidikan Dan Konseling (Jpdk), 3(2), 1-8. Https://Doi.Org/10.31004/Jpdk.V3i2.1615

Hartini, S., Siregar, M., \& Arifi, A. (2020). Implementasi Pendidikan Karakter Di Mts Negeri Kabupaten Klat. Al-Asasiyya: Journal Of Basic Education, 4(1), 14-29.

Kamila, Jenisa T., \& Dewi, D. A. (2021). Pentingnya Mengenalkan Pancasila Dan Contoh Penerapan Nilai Nilai Pancasila Sejak Anak Berusia Dini. Indonesian Journal Of Mustidisiplinary Islamic Studies, 2(2), $81-92$.

Khaulani, F., S, N., \& Irdamurni, I. (2020). Fase Dan Tugas Perkembangan Anak Sekolah Dasar. Jurnal Ilmiah Pendidikan Dasar, 7(1), 51. Https://Doi.Org/10.30659/Pendas.7.1.51-59

L, S. (2019). Pendidikan Kewarganegaraan Sebagai Pendidikan Nilai Dan Pendidikan Hukum Dalam Mewujudkan Warga Negara Yang Cerdas Dan Baik (Smart And Good Citizen). Supremasi: Jurnal Pemikiran, Penelitian Ilmu-Ilmu Sosial, Hukum Dan Pengajarannya, 14(2).

Ma’mur, J. (2016). Buku Panduan Internalisasi Pendidikan Karakter Di Sekolah. Diva Press.

Muchtarom, M. (2017). Pendidikan Karakter Bagi Warga Negara Sebagai Upaya Mengembangkan Good Citizen. Pkn Progresif, 12(1), 543-552.

Putri, R., Lestari, A., Dewi, D. A., Pendidikan, U., Kampus, I., Cibiru, D., Guru, P., \& Dasar, S. (2021). Sebagai Smart And Good Citizen Di Era Disrupsi Rizka Putri Ayuning Lestari Fajar, Dinie Anggraeni Dewi Abstrak. 6(1), 79-92.

Putri, S. B., \& Dewi, D. A. (2021). Reaktualisasi Pendidikan Kewarganegaraan Bagi Generasi Milenial. Jurnal Pendidikan Dan Konseling (Jpdk), 3(2).

S, L. A. (2020). Tantangan Pendidikan Kewarganegaraan Pada Revolusi 4.0. Ensiklopedia Social Review, 2(3), 333-339.

Samani, M., \& Hariyanto. (2012). Konsep Dan Model Pendidikan Karakter. Remaja Rosdakarya.

Samsuri. (2011). Pendidikan Kewarganegaraan Sebagai Wahana Membangun Karakter Warga Negara Demokratis. In Pendidikan Karakter Dalam Perspektif Teori Dan Praktik (Pp. 356-383). Uny Press.

Santika, I. G. N., Kartika, I. M., \& Rini Wahyuni, N. W. (2019). Pendidikan Karakter: Stusi Kasus Peranan Keluarga Terhadap Pembentukan Karakter Anak Ibu Sunah Di Tanjung Benoa. Jurnal Kajian Pendidikan Widya Accarya Fkip Universitas Dwijendra, 10(1).

Sardiman, A. M. (2020). Interaksi \& Motivasi Belajar Mengajar. Pt Rajagrafindo Persada.

Wibowo, A. (2012). Pendidikan Karakter: Strategi Membangun Karakter Bangsa Berperadaban. Pustaka Pelajar.

Winarno. (2012). Karakter Warga Negara Yang Baik Dan Cerdas. Pkn Progresif, 7(1), 54-62.

Winarno. (2013). Pembelajaran Pendidikan Kewarganegaraan: Isi, Strategi, Dan Penilaian (1st Ed.). Bumi Aksara.

Winataputra, U. S. (2016). Posisi Akademik Pendidikan Kewarganegaraan (Pkn) Dan Muatan/Mata Pelajaran Pendidikan Pancasila Dan Kewarganegaraan (Ppkn) Dalam Konteks Sistem Pendidikan Nasional. Jurnal Moral Kemasyarakatan, 1(1), 15-36.

Zubaedi. (2011). Desain Pendidikan Karakter. Kencana Prenada Media Group. 